\title{
PENGARUH MODEL PROBLEM BASED LEARNING (PBL) DENGAN MENGGUNAKAN MINP MAPLE UNTUK MENINGKATKAN HASIL BELAJAR PADA MATERI TERMOKIMIA
}

\section{THE EFFECT OF THE PROBLEM-BASED LEARNING (PBL) MODEL USING THE MINP MAPLE TO IMPROVE LEARNING OUTCOMES IN THERMOCHEMICAL MATERIALS}

\author{
Hisar Marulitua Manurung ${ }^{1}$ Eva Pratiwi Pane ${ }^{2}$ \\ Program Studi Pendidikan Kimia Universitas HKBP Nommensen Pematangsiantar \\ *Corresponding author: hisarmanurung03@gmail.com
}

\begin{abstract}
ABSTRAK
Penelitian ini bertujuan untuk mengetahui pengaruh model problem based learning (PBL) menggunakan mind maple untuk mengningkatkan hasil belajar siswa pada materi termokimia. Metode penelitian adalah metode eksperimen semu (quasi eksperimen) yang populasinya seluruh siswa kelas XI-MIA di SMA Negeri 15 Medan. Sampel penelitian sebanyak 64 siswa yang ditentukan secara random sampling. Sampel tersebut terdiri dari 2 kelas yaitu, kelas eksperimen (siswa yang dibelajarkan dengan mode PBL tanpa media dan kelas kontrol (siswa yang dibelajarkan dengan model PBL dengan mind maple). Instrumen yang digunakan dalam penelitian ini berupa tes tertulis pilihan berganda untuk mengukur hasil belajar siswa. Hasil penelitian menunjukkan peningkatan hasil belajar siswa dari nilai KKM pada kelas eksperimen sebesar 2,55 dan penurunan hasil belajar siswa dari nilai KKM pada kelas kontrol sebesar 0,80. Terdapat pengaruh model problem based learning (PBL) menggunakan mind maple untuk mengningkatkan hasil belajar siswa pada materi termokimia dengan taraf signifikansi $0,021<0,05$.
\end{abstract}

Kata kunci: PBL; Mind Maple; Termokimia.

\begin{abstract}
This study aims to determine the effect of the problem based learning (PBL) model using mind maple to improve student learning outcomes in thermochemical material. The research method is a quasiexperimental method, the population of which is all students of class XI-MIA at SMA Negeri 15 Medan. The research sample was 64 students who were determined by random sampling. The sample consisted of 2 classes, namely, the experimental class (students who were taught using PBL without media and the control class (students who were taught using the PBL model with mind maple). The instrument used in this study was a multiple choice written test to measure student learning outcomes. The results showed an increase in student learning outcomes from the KKM score in the experimental class by 2.55 and a decrease in student learning outcomes from the KKM score in the control class by 0.80.There was an effect of the problem based learning (PBL) model using mind maple to improve learning outcomes. students on thermochemical material with a significance level of $0.021<0.05$
\end{abstract}

Keywords: PBL; Mind Maple; Thermochemical 


\section{PENDAHULUAN}

Pembelajaran adalah proses pengajaran yang dilakukan oleh guru untuk mengelola tingkah laku pada kondisi tertentu atau menghasilkan perubahan posistif terhadap situasi tertentu (Sagala, 2012). Pembelajaran yang baik apabila penerapannya dilaksanakan secara interaktif, inspiratif, menyenangkan, menantang, memotivasi siswa untuk berpartisipasi aktif, serta memberikan ruang yang cukup bagi prakarsa, kreativitas, dan kemandirian sesuai dengan bakat, minat, dan perkembangan fisik serta psikologis siswa (Tim \& Kemendikbud, 2017).

Kurikulum 2013 mengutamakan pembelajaran yang mendorong aktivitas fisik dan mental siswa secara optimal. Praktek pembelajaran demikian mendukung tumbuhnya pembelajaran aktif (active learning). Pembelajaran ini menggerakkan seluruh aktivitas fisik dan mental siswa sehingga siswa memiliki banyak pengalaman belajar melalui pemberdayaan potensi dirinya. Proses pembelajaran penyingkapan/penelitian (discovery/inquiry learning) dan pembelajaran yang menghasilkan karya kontekstual berbasis masalah (problem base learning). Pembelajaran ini melatih siswa mampu berpikir kritis, kreatif, kolaboratif, dan komunikatif sebagaimana dibutuhkan dalam kehidupan abad 21 (KEMENDIKBUD, 2016).

Berdasarkan hasil persentase penguasaan materi kimia yang dikeluarkan Kemendikbud dari tahun pelajaran 2014/2015-2016/ 2017 salah satu materi yang persentase kepahaman siswanya rendah adalah materi yang berkaitan dengan perhitungan dan penguasaan konsep karena materi tersebut merupakan konsep yang tidak cukup hanya dengan dihafal saja namun terdapat konsep-konsep yang perlu diobservasi melalui praktikum maupun diskusi dalam kelompok, sehingga dengan kegiatan ini diharapkan dapat lebih memahami konsep (KENDAL, n.d.). Salah satu faktor yang mempengaruhi pemahaman konsep siswa adalah metode mengajar (). Kesulitan peserta didik dalam menyelesaikan soal-soal kimia mengakibatkan pemahaman konsep peserta didik rendah sehingga 54,2\% peserta didik menyatakan mereka kurang percaya diri dalam menyampaikan pendapat dalam pelajaran kimia (Mutiara \& Hidayat, 2016). Pelajaran kimia adalah salah satu pelajaran yang kompleks baik berupa hitungan maupun pemahaman konsep. Konsep kimia yang bersifat faktual juga abstrak membuat siswa kurang berminat mempelajaranya (Kean \& Middlecamp, 1985).

Problem Based Learning (PBL) adalah sebuah kurikulum yang merencanakan pembelajaran untuk mencapai suatu tujuan instuksional (Hung, 2009). Guru mendesain pembelajaran dengan memberikan permasalahan yang melibatkan keterampilan berpikir siswa dan melibatkan proses menganalisis berdasarkan permasalahan yang sebenarnya. PBL menekankan belajar sebagai proses yang melibatkan pemecahan masalah dan berpikir kritis dalam konteks yang sebenarnya sehingga dapat mengembangkan potensi dan meningkatkan hasil belajar siswa (Glazer, 2001). model PBL dapat meningkatkan hasil belajar siswa pada aspek kognitif, afektif dan psikomotorik (Abdullah \& Ridwan, 2008). PBL juga dapat mengantar siswa untuk menyelesaikan permasalahan hidup melalui proses menemukan, belajar dan berpikir secara independen (Tan, 2009).

Mind maple merupakan aplikasi yang digunakan untuk membuat mind maping melalui piranti lunak untuk menempatkan informasi ke dalam otak dan mengambilnya kembali ke luar otak. Bentuk mind mapping seperti peta sebuah jalan di kota yang mempunyai banyak cabang. Seperti halnya peta jalan kita bisa membuat pandangan secara menyeluruh tentang pokok masalah dalam suatu area yang sangat luas. Dengan sebuah peta kita bisa merencanakan sebuah rute yang tercepat dan tepat dan mengetahui kemana kita akan pergi dan dimana kita berada. Mind mapping bias disebut sebuah peta rute yang digunakan ingatan, membuat kita bisa menyusun fakta dan fikiran sedemikian rupa sehingga cara kerja otak kita yang alami akan dilibatkan sejak awal sehingga mengingat informasi akan lebih mudah dan bisa diandalkan daripada menggunakan teknik mencatat biasa (Buzan, 2012).

Mind maple dapat dimanfaatkan oleh guru sebagai sarana pendukung pembelajaran yang akan dilakukan selama belajar. Aplikasi tersebut dirancang untuk memudahkan guru untuk membuat mind maping secara langsung tanpa menggunakan alat tulis. Variasi mind maping yang terdapat pada aplikasi tersebut sangat beragam sehingga mind mapping yang ditampilkan oleh guru disaat mengajar dapat mengatasi kejenuhan siswa selama mengikut pembelajaran di kelas. Berdasarkan hasil penelitian bahwa kegiatan pembelajaran dengan penerapan model peta pikiran (Mind Mapping) diupayakan mampu menarik perhatian dan minat siswa, mendukung kegiatan siswa dalam menemukan pokokpokok pikiran pada materi tertentu (Aprinawati, 2018). 
Berdasarkan penjelasan diatas sehingga dilakukan penelitian dengan judul "Pengaruh Model Problem Based Learning (PBL) Menggunakan Mind Maple untuk Meningkatkan Hasil Belajar pada Materi Termokimia".

\section{METODE PENELITIAN}

\subsection{Jenis Penelitian}

Penelitian ini menggunakan pendekatan kuantitatif dengan menggunakan metode eksperimen semu (quasi eksperimen) factorial $2 \times 2$, yang terdiri dari 2 kelas, yaitu kelas eksperimen dan kelas kontrol dengan membuat suatu perlakuan dalam pembelajaran yaitu proses pembelajaran dengan model PBL dengan Mind Maple dan pembelajaran model PBL tanpa Mind Maple.

\subsection{Waktu dan Tempat Penelitian}

Penelitian ini telah dilaksanakan di SMA Negeri 15 Medan kelas XI-MIA semester ganjil Tahun Ajaran 2018/2019 pada bulan September sampai dengan Desember 2018.

\subsection{Target/Subjek Penelitian}

Populasi penelitian adalah seluruh siswa kelas XI-MIA di SMA Negeri 15 Medan. Sampel penelitian terdiri dari 2 kelas yang berjumlah 64 siswa yang diambil dengan teknik random sampling.

Diurai dengan jelas dalam bagian ini. Perlu dituliskan juga teknik memperoleh subjek penelitian untuk kualitatif dan atau teknik samplingnya untuk penelitian kuantitatif.

\subsection{Prosedur}

Adapun prosedur pelaksanaan penelitian ini adalah sebagai berikut :

a. Menyediakan RPP (Rancangan Pelaksanaan Pembelajaran) sesuai indikator yang akan dicapai siswa dengan media pembelajaran yaitu Mind Maple dengan mengguanakn instrumen tes tertulis berupa pilihan berganda untuk mengukur hasil belajar siswa.

b. Menentukan populasi dan sampel penelitian.

c. Menerapkan model pembelajaran pada masing-masing kelas eksperimen dan kelas kontrol pada pokok bahasan termokimia : kelas eksperimen yang mendapat pembelajaran dengan model PBL dengan Mind Maple dan kelas kontrol yang mendapat pembelajaran dengan model PBL tanpa Mind Maple

d. Mengadakan tes pada siswa setelah dilakukan proses pembelajaran pada pokok bahasan termokimia. Tes ini dilakukan untuk menguji penguasaan siswa pada materi termokimia setelah dilakukan pembelajaran.

e. Mengolah data hasil belajar.

f. Menganalisis data yang diperoleh dari penelitian serta membuat suatu kesimpulan.

\subsection{Data, Instrumen, dan Teknik Pengumpulan Data}

Setelah diberikan perlakukan pada kelas eksperimen dan kelas kontrol, maka siswa diberikan tes tertulis berupa pilihan berganda untuk memperoleh data hasil belajar siswa. Sebelumnya tes tertulis berupa pilihan berganda tersebut terlebih dahulu divadasi oleh validator ahli sehingga instrumen yang digunakan layak untuk diberikan kepada siswa. Instrumen yang digunakan terdiri dari 20 butir soal untuk mengukur hasil belajar siswa pada materi termokimia. Tes tersebut dengan tingkat kesukaran yang bervariasi mulai dari tingkat mengingat (C1) sampai dengan mensintesis (C5). Instrumen yang telah selesai dikerjakan siswa dikumpulkan untuk dilakukan penilaian dengan ketentuan butir soal yang benar akan diberikan skor 5 dan butir soal yang salah tidak diberikan skor (0).

\subsection{Teknik Analisis Data}


Teknik analisis data yang digunakan antara lain : (1) Menghitung tingkat hasil belajar, (2) Pengujian normalitas data, (3) Pengujian homogenitas data, (4) Pengujian hipotesis.

\section{HASIL DAN PEMBAHASAN}

Mind Maple adalah aplikasi yang digunakan untuk membuat mind maping melalui piranti lunak untuk menempatkan informasi ke dalam otak dan mengambilnya kembali ke luar otak. Peran mind maple sangat dibutuhkan agar melalui mind mapping siswa bisa mengklasifikan materi termokimia menurut berdasarkan kajiannya masing-masing dan pada akhirnya siswa dengan mudah memahami pokok bahasan termokimia. Sub pokok bahasan termokimia dengan skala makro yaitu, pengertian termokimia, sub pokok bahasan termokimia dengan skala mikro yaitu, jenis-jenis reaksi termokimia, jenis-jenis perubahan entalpi, hukum Hess, dan menghitung perubahan entalpi reaksi.

Data penelitian hasil belajar siswa diperoleh dari hasil penelitian yang dilakukan di sekolah yang berada di kota Medan Tahun Ajaran 2018/2019. Sekolah yang diteliti yaitu, SMAN 15 diambil sebanyak 2 kelas sebagai sampel dalam penelitian. Kedua kelas tersebut diberikan perlakuan yang berbeda, kelas eksperimen siswa yang belajar menggunakan model PBL dengan mind maple dan kelas kontrol siswa yang belajar dengan model PBL tanpa mind maple. sebelum dilakukan penelitian instrumen kognitifnya divalidasi menggunakan validator ahli. setelah dilakukan penelitian dan diberikan perlakuan yang berbeda untuk masing-masing kelas, maka diperoleh data hasil belajar siswa sebagai berikut.

\section{Tabel 1. Data Hasil Belajar Siswa Kelas Eksperimen (E1) dan Kelas Kontrol (E2) pada Materi} Termokimia.

\begin{tabular}{cc}
\hline Kelas & Hasil Belajar \\
\hline Eksperimen & $77,55 \pm 10,60$ \\
\hline Kontrol & $74,20 \pm 12,06$ \\
\hline
\end{tabular}

Berdasarkan data hasil belajar siswa Tabel 1 bahwa hasil belajar siswa yang dibelajarkan dengan model PBL menggunakan mind maple lebih tinggi daripada hasil belajar siswa yang dibelajarkan dengan model PBL tanpa mind maple. Informasi yang diperoleh dari guru kimia yang mengajar di kelas tempat dilakukannya penelitian bahwa nilai Kriteria Ketuntasan Minimal (KKM) mata pelajaran kimia adalah 75. Data tersebut menunjukkan bahwa kelas eksperimen dapat mencapai nilai KKM sedangkan kelas kontrol belum mampu mencapai nilai KKM. Selisih kenaikan hasil belajar kelas eksperimen dari nilai KKM mata pelajaran kimia sebesar 2,55 dan selisih penurunan hasil belajar kelas kontrol dari nilai KKM sebesar 0,80.

\subsection{Analisis Data}

\subsubsection{Uji Normalitas}

Adapun program SPSS yang digunakan untuk menganalisis data hasil belajar terdistribusi normal versi 20 dengan menggunakan uji Kolmogorov-Smirnov dengan taraf signifikansi $\alpha=0.05$.

Tabel 2. Uji Normalitas Data Hasil Belajar Siswa Kelas Eksperimen dan Kelas Kontrol pada Materi Termokimia

\begin{tabular}{ccccc}
\hline Kelas & $\begin{array}{c}\text { Kolmogorof-Smirnov } \\
\mathbf{Z}\end{array}$ & Sig. & $\boldsymbol{\alpha}$ & Keterangan \\
\hline Eksperimen & 0,561 & 0,621 & 0.05 & Terdistribusi Normal \\
\hline Kontrol & 0,512 & 0,573 & 0.05 & Terdistribusi Normal \\
\hline
\end{tabular}

Berdasarkan Tabel 2 menunjukkan bahwa nilai taraf signifikansi $\alpha>0,05$ berarti data terdistribusi normal. Data hasil belajar siswa yang diperoleh pada kelas eksperimen dan kelas kontrol terdistribusi normal. 


\subsubsection{Uji Homogenitas}

Adapun program SPSS yang digunakan untuk menganalisis data hasil belajar yang homogeny adalah versi 20 dengan menggunakan uji Lavene dengan taraf signifikansi $\alpha=0.05$.

\section{Tabel 3. Uji Homogenitas Data Hasil Belajar Siswa Kelas Eksperimen dan Kelas Kontrol pada Materi Termokimia}

\begin{tabular}{ccccc}
\hline Data & Levene Statistik & Sig. & $\boldsymbol{\alpha}$ & Keterangan \\
\hline Hasil Belajar & 0,552 & 0,578 & 0.05 & Bersifat Homogen \\
\hline
\end{tabular}

Berdasarkan Tabel 3 menunjukkan bahwa $\alpha>0,05$ berarti data bersifat homogen. Data hasil belajar siswa yang diperoleh menunjukkan bahwa data tersebut bersifat homogen.

\subsubsection{Pengujian Hipotesis}

Hipotesis yang diuji dalam penelitian ini menggunakan uji $t$, yaitu Pengaruh model PBL menggunakan mind maple untuk meningkatkan hasil belajar pada materi termokimia. Data hasil belajar yang diperoleh dengan ketentuan benar mendapat skor 5 dan salah tidak mendapat skor (0) dengan menggunakan instrumen tes tertulis berupa pilihan berganda.

Tabel 4. Uji Hipotesis Hasil Belajar dengan Model PBL Menggunakan Mind Maple pada Materi Termokimia

\begin{tabular}{cccccc}
\hline & \multicolumn{5}{c}{ Uji t } \\
\cline { 2 - 6 } & Sum of Squares & df & $\begin{array}{c}\text { Mean } \\
\text { Square }\end{array}$ & F & Sig. \\
\hline Between Groups & 3832.223 & 2 & 2086.445 & 24.218 & .021 \\
\hline Within Groups & 21246.381 & 64 & 75.352 & & \\
\hline Total & 31002.330 & 66 & & & \\
\hline
\end{tabular}

Dengan memperhatikan Tabel 4 hasil belajar siswa yang diperoleh keseluruhannya Secara signifikan kedua kelas yang memiliki pengaruh yang signifikan berada pada kelas eksperimen, hasil uji hipotesis diperoleh taraf signifikansi hipotesis sebagai berikut bahwa taraf signifikansi sebesar $0,021<0,05$ yang berarti Ho ditolak dan Ha diterima. Maka dapat disimpulkan bahwa "ada pengaruh model PBL menggunakan mind maple untuk meningkatkan hasil belajar pada materi termokimia".

Berdasarkan hasil analisis data diperoleh berpikir kreatif mahasiswa sebagai berikut :

1. Kelas Eksperimen yang dibelajarkan dengan model PBL menggunakan mind maple menunjukkan peningkatan hasil belajar sebesar 2,55 dari nilai KKM mata pelajaran kimia.

2. Kelas control yang dibelajarkan dengan model PBL tanpa mind maple menunjukkan terjadi penurunan hasil belajar sebesar 0,80 dari nilai KKM mata pelajaran kimia.

\section{SIMPULAN DAN SARAN}

\section{1 Simpulan}

Berdasarkan hasil data yang diperoleh, maka dapat diambil suatu kesimpulan adanya perbedaan hasil belajar siswa kelas eksperimen yang dibelajarkankan dengan model PBL menggunakan mind maple sebesar 77,55 dan hasil belajar siswa kelas kontrol yang dibelajarkan dengan model PBL tanpa mind maple sebesar 74,20.

\section{2 Saran}

Berdasarkan hasil analisis data, maka disarankan hal-hal berikut : 
1. Model pembelajaran PBL ini dapat digunakan sebagai alternatif dalam pembelajaran pada pokok bahasan termokimia

2. Media pembelajaran menggunakan mind maple sangat baik digunakan sehingga dianjurkan agar sekolah dapat menerapkannya .

3. Peneliti harus lebih selektif dalam penggunaan waktu dalam palaksanaan pembelajaran.

4. Kepada peneliti selanjutnya yang ingin meneliti permasalahan yang sama disarankan melakkukan penelitian pada lokasi dan materi yang berbeda serta terlebih dahulu memperhatikan kelemehan-kelemahalam dalam penelitian ini untuk mencapai hasil belajar yang lebih baik.

5. Kepada peneiliti selanjutnya dianjurkan untuk memilih instrumen yang bervariasi tingkat kesulitannya, agar nilai hasil kemampuan yang dimiliki siswa mampu mencapai KKM.

\section{DAFTAR PUSTAKA}

Abdullah, A. G., \& Ridwan, T. (2008). Implementasi Problem Based Learning (PBL) pada Proses Pembelajaran di BPTP Bandung. Prosiding UPI, 1-10.

Aprinawati, I. (2018). Penggunaan Model Peta Pikiran (Mind Mapping) untuk Meningkatkan Pemahaman Membaca Wacana Siswa Sekolah Dasar. Jurnal Basicedu, 2(1), 140-147.

Buzan, T. (2012). Mind mapping: scientific research and studies. London: Think Buzan Ltd.

Glazer, E. (2001). Problem based instruction. Emerging Perspective on Learning, Teaching, and Technology.

Hung, W. (2009). The 9-step problem design process for problem-based learning: Application of the 3C3R model. Educational Research Review, 4(2), 118-141.

Kean, E., \& Middlecamp, C. (1985). Panduan belajar kimia dasar. Jakarta: Gramedia.

KEMENDIKBUD, R. I. (2016). Peraturan Menteri Pendidikan Dan Kebudayaan Republik Indonesia nomor 22 tahun 2016. Kemendikbud RI, STANDAR PROSES PENDIDIKAN DASAR DAN MENENGAH, 1-15.

KENDAL, K. X. I. D. I. M. A. N. (n.d.). PENGEMBANGAN MODUL PEMBELAJARAN KIMIA BERPENDEKATAN CHEMO-ENTREPRENEURSHIP (CEP) PADA MATERI HIDROLISIS GARAM BAGI PESERTA DIDIK.

Mutiara, S. A., \& Hidayat, I. (2016). Penerapan Model Pembelajaran Problem Based Learning untuk Meningkatkan Pemahaman Konsep Peserta Didik pada Pelajaran Kimia di Kelas XI MIA 3 SMAN 1 Indralaya. J Penelit Pendidik Kim, 3(2), 179-185.

Sagala, S. (2012). Konsep dan Makna Pembelajaran. Bandung: Alfabeta, 2009. Cet. VII.

Tan, O. S. (2009). Problem-based learning and creativity. Cengage Learning Asia.

Tim, P. P. K., \& Kemendikbud, P. (2017). Konsep dan Pedoman Penguatan Pendidikan Karakter. Jakarta: Kemendikbud. 